\title{
Inocuidad y alertas alimentarias: una visión
} léxico-traductológica (inglés-español) ${ }^{1}$

\section{Resumen}

El presente trabajo tiene como objetivo estudiar la traducción de un tipo de texto, la alerta alimentaria, del que existen escasos trabajos hasta la fecha. Para ello, se ha compilado un corpus compuesto por más de 1200 alertas alimentarias de los Estados Unidos, escritas originariamente en lengua inglesa y traducidas al español. También se ha compilado un corpus de referencia con alertas alimentarias y textos relacionados procedentes de Colombia, España y México. Se han estudiado en primer lugar algunos aspectos generales (rasgos ortográficos, traducción de topónimos y traducción de unidades de medida), para seguidamente hacer un análisis de la traducción de las palabras clave más relevantes del corpus que guardan relación con la inocuidad alimentaria. Este estudio concluye que, en líneas generales, la traducción al español de los rasgos mencionados es adecuada, aunque las omisiones e imprecisiones, cualitativamente significativas, podrían comprometer la efectividad de las alertas, al tiempo que podrían poner en riesgo la salud de los consumidores.

Palabras clave: traducción en la industria alimentaria; seguridad alimentaria; alertas alimentarias; traducción inglés-español; estudios basados en corpus.

\section{Food Safety and Recall Releases: A Lexical-Translational Perspective} (English-Spanish)

\begin{abstract}
This paper studies the translation of a specific type of text, the recall release, which has not been thoroughly analyzed until now. To this end, a corpus containing more than 1,200 recall releases from the United States, originally written in English and translated into Spanish, has been compiled. An additional reference corpus, consisting of recall releases and related texts from Colombia, Spain, and Mexico, was also compiled. First, some general aspects were analyzed (orthography and translation of state names and units of measurement). Second, the translation of the most relevant keywords from the corpus that are linked to food safety was studied. This article concludes that, in general terms, the translation of the aforementioned elements into Spanish is adequate, although the
\end{abstract}

1 El presente artículo es producto del proyecto de investigación "entiTur: sistema de monitorización de opinión de usuarios de recursos turísticos andaluces basado en análisis de sentimiento y análisis visual” (referencia UMA18-FEDERJA-158), con fechas de ejecución entre noviembre de 2019 y noviembre de 2021. 
omissions and inaccuracies, qualitatively speaking, might compromise the effectiveness of the recall releases and pose a risk to the health of consumers.

Keywords: Food-industry translation; food safety; recall releases/alerts; English-Spanish translation; corpus-based studies.

Innocuité et alertes alimentaires : une vision lexico-traductologique (anglais/espagnol)

\section{Résumé}

Le présent travail vise à étudier la traduction d'un type de texte, l'alerte alimentaire, dont il existe peu de travaux à ce jour. Pour cela, on a compilé un corpus, composé de plus de 1200 alertes alimentaires en provenance des États-Unis, rédigés à l'origine en anglais et traduits en espagnol. Dans le même temps, un corpus de référence contenant des alertes alimentaires et des textes connexes de Colombie, d'Espagne et du Mexique a également été établi. Dans un premier temps, certains aspects généraux ont été étudiés (caractéristiques orthographiques, traduction des noms de lieux et traduction des unités de mesure), pour ensuite analyser la traduction des mots-clés les plus pertinents du corpus, liés à la sécurité alimentaire. Cette étude conclut que, de manière générale, la traduction en espagnol des as- 
pects susmentionnés est adéquate, bien que les omissions et les inexactitudes, qualitativement significatives, puissent compromettre l'efficacité des alertes, tout en mettant en danger la santé des consommateurs.

Mots-clés : traduction dans l'industrie alimentaire; innocuité alimentaire; alertes alimentaires; traduction anglais-espagnol; études basées sur corpus.

\section{Introducción}

Las enfermedades de origen alimentario tienen un impacto enorme en la población de los Estados Unidos: cada año, uno de cada seis estadounidenses (o 47,8 millones de personas) enferma a causa de intoxicaciones alimentarias; de ellos, más de 127000 personas precisan de hospitalización y se producen más de 3000 fallecimientos (Scallan et al., 2011, p.16). De todas las retiradas de productos que se realizan en los Estados Unidos, las del segmento de alimentos constituyen la categoría más grande (RASMAS, 2010, citado en Carlson y Peake, 2012, p. 12). El UsDA (United States Department of Agriculture), mediante una de sus unidades operativas, el FsIs (U.S. Food Safety and Inspection Service), es el organismo encargado de supervisar las alertas de retirada de alimentos que tienen relación con productos cárnicos, de pescados del orden Siluriformes o elaborados con huevo procesado (U.S. Food Safety and Inspection Service, 2021), mientras que la FDA (Food and Drug Administration) se ocupa de supervisar el resto de alimentos. En 2019, último año del que se tienen cifras completas, el Fsis publicó 124 alertas de retirada de alimentos - de las cuales tres cuartas partes pertenecían a alertas de clase I, el nivel superior-, y los productos sometidos a retirada sumaron más de 9200 toneladas (U.S. Food Safety and Inspection Service, 2020). La razón más habitual para la retirada corresponde a la categoría Otros — problemas de etiquetado y productos sin certificado de inspección, entre otros- (35 alertas), seguida de la presencia de cuerpos extraños (34) y de alérgenos no declarados (32). Las alertas por bacterias suman 16: Escherichia coli (7), Listeria monocytogenes (6) y Salmonella (3). Por último, se localizaron sustancias no declaradas y defectos de procesado (4 y 3 alertas, respectivamente).

Estas enfermedades no solo tienen un impacto en la salud de los consumidores, sino que también pueden tener repercusiones económicas muy importantes: una alerta alimentaria puede desencadenar una crisis de reputación en la empresa responsable, pero también puede afectar el producto o alimento en cuestión y traspasar incluso las fronteras del país (Hallman y Cuite, 2009, p. 3; Charlebois et al., 2015). Sirva como ejemplo lo sucedido en los Estados Unidos ante un caso de contaminación por Escherichia coli en espinacas en el año 2006: las consecuencias sanitarias fueron graves, con 200 casos, 100 hospitalizaciones y 3 fallecimientos, pero también tuvo efectos devastadores en el sector de la espinaca, con pérdidas estimadas de entre 74 y $100 \mathrm{mi}$ llones de dólares (Wu, 2017, p. 23).

Según afirman Hallman y Cuite —en un trabajo referido a la seguridad alimentaria de los Estados Unidos, pero que podría ser extensible a otros países-, el hecho de que se haya producido en los últimos años un número elevado de brotes ha tenido como resultado un aumento de la atención sobre el sistema alimentario. Al tiempo, ha calado entre la población la sensación de que se producen retiradas de alimentos con una frecuencia cada vez mayor. Los autores sostienen además que los avances técnicos, con mejoras en la detección de los brotes y una mayor capacidad de identificación de las cepas patógenas, harán que en el futuro haya aún más retiradas de alimentos y, por lo tanto, se producirá un aumento de los avisos y las comunicaciones. Como consecuencia de todo esto, "proporcionar a los consumidores información sobre las retira- 
das de alimentos que sea clara, motivadora y precisa será más relevante que nunca"2 (Hallman y Cuite, 2009, p. II).

El objetivo del presente trabajo es realizar un estudio traductológico y terminológico que profundice en el conocimiento de las alertas de retiradas de alimentos, el tipo de texto mediante el que se notifica a la población el riesgo de consumir un producto concreto. Se trata de un texto que hasta donde sabemos no se ha estudiado desde el punto de vista de la traducción, a pesar de su enorme relevancia en cuanto a sus posibles consecuencias sanitarias y económicas. En lo que respecta a la organización de este trabajo, primeramente (apartado2), veremos muy someramente qué finalidad tienen las alertas alimentarias y cómo se clasifican en los Estados Unidos, de manera concreta en el caso del FSIs. Seguidamente (apartado 3), se enunciará la línea en la que se inserta nuestra investigación - la de la alimentación y la inocuidad alimentaria desde el punto de vista de la traducción-. En el apartado 4 se describen los dos corpus compilados para los fines de esta investigación, que se explotan en los dos apartados subsiguientes: apartado 5 -con una breve caracterización de algunos rasgos de las alertas en la lengua inglesa-y apartado 6 , donde se verá cómo es la traducción al español de determinados rasgos generales y se analizará el léxico relacionado con la inocuidad alimentaria de mayor relevancia en el corpus de alertas alimentarias traducidas.

\section{Alertas alimentarias en los Estados Unidos}

2 "providing clear, motivating, and accurate communication about food recalls to the public will be more essential than ever". La traducción al español de todas las citas textuales en lengua inglesa ha corrido a cargo del autor del artículo.
El sistema de seguridad alimentaria de los Estados Unidos ocupa el tercer puesto mundial, de acuerdo con la edición más reciente del Global Food Security Index (The Economist Intelligence Unit, 2019). Dos de sus puntos fuertes radican en la presencia y la calidad de los programas de seguridad alimentaria (100 puntos sobre 100), y la seguridad alimentaria del país (99,5/100). En los Estados Unidos, las alertas alimentarias no parten del organismo supervisor, sino de las propias empresas de la industria alimentaria: estas notifican las retiradas de alimentos (food recalls, en inglés). E1 papel que desempeña el Fsis ante una alerta de retirada de alimentos es el siguiente:

Cuando la empresa comienza un proceso de retirada, el FSIS emite de inmediato un comunicado de prensa para notificarlo al público, lo difunde en su sitio web y proporciona información directamente a los interesados -incluidos el Congreso, los medios de comunicación, funcionarios federales, estatales y municipales, y electores -.$^{3}$ (Brougher y Greene, 2000, sec. Summary)

Es importante precisar además que el comienzo de la retirada suele ser voluntario por parte de la empresa; el papel del Fsis es habitualmente de coordinación con la empresa y de aseguramiento de que el proceso de retirada del alimento en cuestión se haya realizado correctamente (U.S. Food Safety and Inspection Service, 2013a, sec. Attachment3). Las alertas de retirada de alimentos del Fsis se clasifican en tres tipos o classes, a saber (Brougher y Greene, 2000, pp. 5-6; National Food Service Management Institute, 2012, p. 5):

Class I, que se emiten cuando "hay una probabilidad razonable de que el consumo del pro-

3 "Once the company initiates a recall, FsIs immediately issues a press release to notify the public, posts it on its website, and provides information directly to stakeholders-including Congress, the media, federal, state, and local officials, and constituents." 
ducto tenga consecuencias adversas graves o sea causa de muerte" 4 (U.S. Food Safety and Inspection Service, 2013a, p. 2). Son ejemplos de este tipo de retirada la presencia de Escherichia coli en carne picada de ternera, la detección de salmonela en mantequilla de cacahuete y la localización de alérgenos no declarados en la composición de los alimentos.

Class II, referidas a situaciones con probabilidades remotas de que se produzcan consecuencias adversas por el consumo del producto, como puede ser por la aparición de cuerpos extraños en los alimentos.

Class III, para casos en los que el consumo del producto no tendrá consecuencias adversas en la salud de los consumidores. Determinan esta clasificación "[p]roblemas leves de etiquetado, como, por ejemplo, formatos no adecuados o ingredientes no declarados que no sean alérgenos"5 (National Food Service Management Institute, 2012, p. 5).

Como norma general, el FsIs no suele emitir alertas sobre la retirada de alimentos de la clase III (U.S. Food Safety and Inspection Service, 2013a, p. 10), por lo que los textos estudiados en el presente artículo hacen referencia esencialmente a las clases I y II. Un aspecto de crucial importancia es la notificación de la retirada a los distribuidores y, de forma muy especial para los fines de este estudio, a los consumidores. Aunque no existe en los Estados Unidos obligación legal de notificar las retiradas de alimentos, el FsIs informa a los consumidores mediante la emisión de comunicados de prensa y publicando mensajes en su sitio web (Brougher y Greene, 2000, p. 7; U.S. Government Accountability Office, 2004, p. 9). Para que la comunicación de tales retiradas sea efectiva, consideran Hallman

4 "there is a reasonable probability that the use of the product will cause serious, adverse health consequences or death."

5 "[m]inor labeling problems, such as improper format or undeclared ingredients that are not allergens." y Cuite $(2009$, p. 3) que las comunicaciones deben reunir las tres características siguientes:

- Ser lo suficientemente amplias como para llegar a todos los consumidores potencialmente afectados, con el fin de ponerles sobre aviso de la retirada de un alimento que podrían haber adquirido.

- Proporcionar información lo suficientemente detallada para que los consumidores sepan con certeza de qué productos se ha dado la orden de retirada y de cuáles no, de modo que puedan desecharlos correctamente.

- Ser lo suficientemente rotundas como para captar la atención de los consumidores, de manera que les motiven a buscar los productos sometidos a la retirada y, en caso de que los localicen, tomar las medidas oportunas.

No obstante, es preciso tener en cuenta que la emisión de las alertas de alimentos ha de hacerse sin provocar temor innecesario entre la población, pues ello

puede llevar a los consumidores a evitar alimentos que son saludables y nutritivos, y no forman parte de la retirada. Si no se hace de esta forma, las empresas (y a menudo sectores agrícolas o alimentarios enteros) perderán una parte sustancial de sus bases de clientes, incluidos los mercados de exportación. ${ }^{6}(\mathrm{Ha}-$ llman y Cuite, 2009, p. 3)

Aunque el sistema de información de alertas estadounidense es bastante claro, ya que la información sobre retiradas de alimentos se puede localizar con relativa facilidad, si se compara con las instituciones que se han con-

6 "may lead consumers to avoid otherwise healthy, nutritious foods that are not part of the recall. Failure to do so can result in companies (and often, entire agricultural or food sectors) losing substantial portions of their customer bases, including export markets.” 
sultado para elaborar el corpus de referencia, lo cierto es que aún hay margen para la mejora. Uno de los principales escollos es lograr que el mensaje llegue a los consumidores de forma efectiva y que produzca en ellos la respuesta necesaria: descartar el alimento si lo tienen en casa, no descartar lo que no esté contaminado y volver a consumir el producto cuando sea nuevamente seguro.

Una dificultad adicional para la comunicación de estos mensajes atañe especialmente al presente estudio: el panorama lingüístico de los Estados Unidos. Según los últimos datos publicados, el $22 \%$ de la población del país habla en casa un idioma distinto al inglés (U.S. Census Bureau, 2019) y, del total de la población, más de 25 millones reconocen hablar inglés "menos que bien" (U.S. Census Bureau, 2015). En cuanto a la importancia de otras lenguas distintas del inglés, el español es sin duda la más habitual: la hablan más de 39 millones de personas en los Estados Unidos o, lo que es lo mismo, el 13,1 \% de la población (Statistical Atlas, 2018). Como consecuencia, "para llegar a todo el público que se pretende es conveniente que la información sobre retiradas de alimentos esté disponible en más idiomas aparte del inglés"8 (Hallman y Cuite, 2009, p. 10), entre otros motivos, afirman Hallman y Cuite, por cuestiones legales, en caso de que la empresa que ha vendido el producto contaminado deba dirimir responsabilidades.

\section{Traducción y alimentación e inocuidad alimentaria}

Es incontestable la relevancia de la alimentación en la sociedad actual desde múltiples puntos de vista: político, económico o cientí-

\footnotetext{
7 "less than well."

8 "to reach all of its intended audiences, food recall information may need to be made available in multiple languages in addition to English."
}

fico, por citar solo unos pocos. Así lo consideran, por ejemplo, Chiaro y Rossato, quienes afirman que existe una tendencia por parte de investigadores, políticos y la sociedad en general a centrarse en "la producción, los costos y el desperdicio de alimentos, en las ventajas de los alimentos ecológicos frente a los modificados genéticamente o en aspectos relevantes desde una perspectiva legal, comola información sobre alimentos o el etiquetado de alimentos" 9 (Chiaro y Rossato, 2015, p. 242). A pesar de este auge, advierten estas mismas investigadoras que ello no se ha visto reflejado en una presencia nutrida de estudios sobre la alimentación desde el prisma de la traducción:

Sin embargo, los aspectos interculturales e interlingüísticos de los alimentos, a medida que traspasan barreras físicas y culturales, permanecen inexplicablemente desatendidos, a pesar de la omnipresencia de los alimentos y la gastronomía en todos los ámbitos de la vida, y pese a una necesidad creciente de traducción de textos relacionados con los alimentos. ¿Podría deberse a que la comida aún se considera un tema sin importancia, doméstico y femenino $[\ldots]]^{?^{10}}$ (Chiaro y Rossato, 2015 , p. 242)

Si bien la afirmación de Chiaro y Rossato es cierta a nuestro juicio, es justo reconocer que han aparecido en los últimos años un número de trabajos de interés que abordan la traducción de aspectos relacionados con la alimentación. Algunos de ellos están recogidos en dos números

9 "food production, food costs, food waste, the merits of organic food vs. genetically modified food, or legally relevant issues such as food information and food labelling."

10 "The cross-cultural and cross-linguistic aspects of food as it travels across physical and cultural boundaries, on the other hand, remain inexplicably neglected, despite the omnipresence of food and eating in every domain of life, and in spite of a growing need for the translation of texts related to food. Could it be that food is still regarded as a trivial, domestic, female topic [...]?" 
especiales, verdaderos precursores de los estudios en este campo: el volumen especial de The Translator, titulado "Food and Translation, Translation and Food" (2015), y el número especial "Semiotics of Food", que publicó la revista Semiotica al año siguiente (2016). Aparte de los artículos de estos dos volúmenes, encontramos también estudios sobre la traducción de cartas de restaurantes (Fuentes-Luque, 2017 y Li, 2019), trabajos que versan sobre la situación de la traducción agroalimentaria (Rodríguez Rodríguez, 2013; Moreno Paz y Rodríguez Tapia, 2015, por ejemplo) y contribuciones sobre la traducción de términos relacionados con la gastronomía desde un enfoque cultural (como Vidal Claramonte y Faber, 2017 y Díaz Flores, 2018). De especial relevancia para los fines de nuestro trabajo son algunas aportaciones sobre la traducción de textos relacionados con el sector alimentario desde una perspectiva de la lingüística de corpus. Nos referimos, aparte del artículo de $\mathrm{Li}$ (2019) recién mencionado, a los trabajos de Ortego-Antón (2019; 2020) y Fernández Nistal (2020), que se ocupan de la traducción de fichas descriptivas de embutidos.

En cuanto al ámbito que nos ocupa aquí, la traducción de alertas de retirada de alimentos, no tenemos constancia de la existencia de trabajos enfocados en su traducción o, de forma más amplia, ni siquiera en textos relacionados con la inocuidad alimentaria. Es más, tampoco hay más llamadas a traducir alertas alimentarias a otras lenguas en los Estados Unidos aparte de la mención de Hallman y Cuite (2009), ya comentada en el apartado anterior. El presente trabajo, por lo tanto, es, si no la primera, una de las primeras aportaciones al estudio de la traducción de alertas alimentarias del inglés al español. Por ese motivo, consideramos que una aproximación desde la lingüística de corpus - algo que, como se ha visto, no es ajeno a los estudios sobre traducción agroalimentaria - puede aportar una vi- sión general óptima para examinar la traducción de este tipo de texto por vez primera.

\section{Características de las alertas alimentarias}

Para los fines de la presente investigación se ha compilado un corpus, denominado ALER_USA (ALERtas alimentarias + USA), que es, de acuerdo con la terminología de McEnery y Hardie (2012, p. 19), un corpus multilingüe de tipo A; además, es un corpus especializado paralelo - con textos originales escritos en inglés y traducidos al español-, unidireccional y alineado en el nivel de la oración (Faya Ornia, 2014, p. 247). ${ }^{11}$ El corpus se compone de todas las alertas alimentarias del Fsis que se encuentran traducidas al español en su sitio web. Para la compilación del corpus se han seguido las premisas recogidas en un trabajo anterior (Leiva Rojo, 2018), mientras que para su explotación se ha empleado la herramienta de análisis Sketch Engine (Kilgarriff et al., 2014).

El corpus ALER_USA consta de 1277 bitextos, de los cuales el más antiguo se remonta al año 2006, mientras que los más recientes son los 19 registros correspondientes a alertas alimentarias emitidas en el año 2020. En cuanto a sus dimensiones, el análisis de Sketch Engine arroja unos resultados de 350682 palabras en el subcorpus en lengua inglesa (ALER_USA/EN), mientras que, para el subcorpus en lengua española, ALER_USA/ES, los resultados son mayores (476191 palabras). De acuerdo con estos datos, el tamaño de ALER_USA es bastante reducido, algo que Zanettin (2012,

11 Tanto este corpus como el corpus de referencia, del que se habla seguidamente, están disponibles para su consulta con fines de investigación. Para ello, envíese un mensaje electrónico al autor de este trabajo (leiva@uma.es) desde una cuenta académica, incluyendo además el nombre de usuario de Sketch Engine. 
p. 152) considera lógico si se tiene en cuenta lo especializado del dominio, el tipo de texto y la propia temática del corpus. Además, al tratarse de un corpus paralelo y alineado, la disponibilidad de los textos es aún más limitada: como muy acertadamente considera Nádvorníková (2017, p. 3), el hecho de tener que localizar textos traducidos y sus correspondientes originales es mucho más complicado que localizar solo textos escritos en una única lengua. No obstante, el tamaño del corpus no debe ser un impedimento para considerarlo útil para los fines de este estudio: de una parte, ALER_USA es exhaustivo, pues recoge todos los textos traducidos al español de alertas alimentarias que aloja el FsIs en su sitio web (además de los textos originales correspondientes); de otra parte, los estudios basados en corpus de tamaño reducido son tan válidos como necesarios (Ross, 2018, p. 2) y constituyen una tendencia más que frecuente en los estudios recientes basados en corpus. Así lo ponen de manifiesto, por ejemplo, Ji (2010, p. 6) $\mathrm{o}$, anteriormente incluso, McEnery y Wilson, quienes afirman lo siguiente: "[u]na evolución que no predijimos fue que los corpus, además de hacerse más grandes, jtambién se harían más pequeños!"12 (citado en Danino, 2018, p. 1).

Se ha compilado también un corpus de referencia, denominado ALER_REF y compuesto por textos escritos originariamente en lengua española. Para este corpus se han seleccionado alertas alimentariasy, antela carencia de estas, otros textos similares de varios organismos oficiales de los tres países hispanohablantes de mayor población, de acuerdo con Fernández Vítores (2020, p. 9). Los organismos en cuestión son la COFEPRIs (Comisión Federal para la Protección contra Riesgos Sanitarios) y la PROFECO (Procuraduría Federal

12 "[i]f there was one development we did not predict it was that, as well as getting larger, corpora would also get smaller!" del Consumidor), de México; el Invima (Instituto Nacional del Vigilancia de Medicamentos y Alimentos), de Colombia; y la AESAN (Agencia Española de Seguridad Alimentaria y Nutrición), de España. ALER_REF tiene un total de 581425 palabras, y se ha buscado que los tres subcorpus (uno por país de procedencia de los textos) tengan un tamaño parecido para que ALER_REF sea lo más equilibrado posible. De esta manera, las palabras de ALER_REF/MÉX (subcorpus de México) suponen el 32,8 \% del corpus de referencia; ALER_REF/COL (Colombia), el 34 \%; y ALER_REF/ESP (España), el $33,2 \%$.

De forma paralela, se ha recurrido también a otro corpus ya compilado, el Corpus del español del siglo XXI (Real Academia Española, n.d.), para suplir las posibles carencias que presente ALER_REF. Además, en este acervo se ha buscado siempre filtrando por textos en español que proceden de los Estados Unidos, algo de gran relevancia para los fines de nuestro trabajo. Así mismo, hemos intentado emplear un corpus específico de textos en español de los Estados Unidos, CORPEEU (Moreno-Fernández, 2019), pero lamentablemente no se encuentra aún disponible para su consulta. ${ }^{13}$

\section{Características de las alertas alimentarias en la lengua de origen}

En la totalidad de las alertas de ALER_USA se advierte un patrón similar en la estructura y organización del mensaje. Ello se debe a que la directiva 8080.1 (U.S. Food Safety and Inspection Service, 2013a, p. 10) determina cómo se debe llevar a cabo el proceso de notificación de la retirada y qué elementos debe contener. De acuerdo con esta directiva, en la comunicación se debe proporcionar información sobre los siguientes elementos (al respecto véanse también

13 F. Moreno-Fernández, comunicación personal, 4 de enero de 2021. 
Brougher y Greene, 2000, p. 11; U.S. General Accounting Office, 2010, p. 28; Haigh y Brubaker, 2010, p. 458):

- Descripción clara - y, si es posible, fotografía- del producto que se somete a la retirada, así como las marcas o los códigos que permitan identificarlo, la razón de la retirada y los posibles riesgos que pueda suponer su consumo.

- Indicaciones a los consumidores sobre cómo manipular el producto en caso de que lo hayan adquirido.

- Nombre y número de teléfono de contacto en la empresa para que los consumidores y medios de comunicación puedan realizar posibles consultas.

- Información general sobre los lugares en los que se ha comercializado el producto.

Además, seincluye en algunoscasosinformación con consejos de conservación de los productos o del manejo de alimentos, siempre en relación con el problema que ha motivado la retirada del producto.

Se ha comprobado no solo que los textos se organizan de acuerdo con una estructura recurrente a lo largo del tiempo, sino también que con gran frecuencia la redacción de oraciones y frases completas es idéntica. Al realizar un análisis de los archivos con SDL Trados Studio 2019 (SDL Group, 2018), las 1277 alertas en inglés ALER_ USA/EN suman un total de 763309 palabras (o 71186 segmentos). Gran parte de ellas se repite a lo largo de los distintos archivos: las coincidencias plenas, repeticiones y repeticiones entre archivos llegan a 447486 palabras (51949 segmentos). ${ }^{14}$

14 Téngase en cuenta que estas cifras no coinciden con el volumen de palabras del subcorpus de textos en inglés (cf. apartado anterior) como consecuencia del alto número de segmentos repetidos en los bitextos. Esto es debido a que, al procesar
Ello quiere decir, por lo tanto, que el porcentaje de segmentos coincidentes supone el 72,97 \% del volumen total de textos en inglés.

Llama la atención, al hilo de lo comentado anteriormentesobrelanecesidaddeproporcionar mensajes claros, que en determinadas ocasiones el FSIs comunica a los consumidores que las alertas no afectan a otros alimentos del mismo tipo, sino que corresponden a casos concretos. Así sucede en el Ejemplo 1, donde se indica que una alerta relativa a carne de ternera solo afecta una marca en particular, y no más productos de carne de ternera del estado de Nebraska. ${ }^{15}$

\section{Ejemplo 1}
ALER_USA/EN0047
Clarification: This recall affects only certain products produced at the Nebraska Beef Ltd. company, located in Omaha. It does not re- late, implicate, or otherwise affect beef in the State of Nebraska. Please note this im- portant distinction.

Para Hallman y Cuite (2009, pp. 68), uno de los problemas de comunicación en las alertas alimentarias es la forma como se denomina el proceso sobre el que se informa a los consumidores. De esta manera, se puede hablar de stock

con SDL Trados Studio 2019 cada bitexto para importarlo a un único archivo en formato TMX, el programa elimina las duplicaciones entre los distintos archivos, de manera que, ante dos pares de segmentos totalmente idénticos tanto en la LO como en la LD, sDL Trados Studio 2019 importa solamente uno.

15 Para los ejemplos tomados del corpus ALER_USA, se emplea la siguiente codificación: nombre del corpus, seguido de indicación del subcorpus (EN para inglés y ES para español) y números identificativos del registro. Téngase en cuenta que el texto de los ejemplos se reproduce tal y como figura en el registro original, lo que incluye también posibles errores mecanográficos o faltas de ortografía. Por último, se ha empleado tipo de letra negrita para destacar aquellos aspectos sobre los que tratan los ejemplos. 
recovery (cuando se retiran los productos antes de llegar a los establecimientos comerciales), market withdrawal (si un producto con un defecto menor, que no afecta a la salud de los consumidores, se retira del establecimiento y se devuelve al fabricante), [voluntary] recall (para indicar retiradas de alimentos potencialmente contaminados que han llegado a la cadena de distribución) y advisory o warning - cuando una agencia federal, habitualmente la FDA advierte de un posible problema por productos contaminados, pero no tiene información suficiente como para que una empresa pueda retirar el producto- (cf. también U.S. Food Safety and Inspection Service, 2013a, p. 2).

Los organismos no suelen notificar los casos en los que se produce algún stock recovery o market withdrawal, y esto tiene su reflejo en el corpus, puesto que solo se registran en ALER_USA/EN dos apariciones de market withdrawal, una de advisory y ningún caso de stock recovery ni de warning. Como es de esperar, en el mismo corpus la mayoría de los casos detectados hacen referencia a las denominadas voluntary recalls (hay 2369 apariciones de recall como sustantivo), aunque curiosamente solo aparece el adverbio voluntary asociado a la retirada de alimentos en cuatro ocasiones (Ejemplo 2).

\section{Ejemplo 2}

ALER_USA/EN0790

FSIS and the company issued the voluntary recall over concerns that some product may be frozen and in consumers' freezers.

\section{Traducción al español de alertas alimentarias del FSIS}

De la ingente cantidad de alertas de retirada de alimentos publicadas por el Fsis en su página web, una parte nada desdeñable se ha traducido a la lengua española. La primera de las alertas traducidas se remonta al año 2006, con una sola alerta traducida, mientras que en 2007 se publican 17. Desde el año siguiente el número de alertas traducidas es bastante significativo, pues se llega a publicar más de una centena de alertas anuales traducidas durante siete años. El año 2020, último del que se incluyen alertas en el corpus, supone un cambio drástico en esta tendencia, pues, con sus 19 registros, es el tercer año con menos alertas traducidas. En cualquier caso, es justo reconocer el esfuerzo del FSIS por ofrecer alertas traducidas al español, sobre todo si se compara con el otro organismo encargado de supervisar la inocuidad alimentaria en los Estados Unidos, la FDA, con un volumen de traducciones significativamente menor. El papel preponderante del español como lengua de interés para la traducción a ojos del fsis es, por lo demás, incontestable: es prácticamente la única lengua a la que se traducen las alertas, pues solo se observa un caso de traducción de la alerta alimentaria también al camboyano y al vietnamita. ${ }^{16}$

Como se ha visto en el apartado anterior, el número tan elevado de repeticiones de los textos en lengua inglesa haría que el recurso a una herramienta de traducción asistida por ordenador fuera eficiente desde el punto de vista del reaprovechamiento de los segmentos. A pesar de haber intentado obtener por varias vías información sobre la forma como se traducen los textos en el FsIs, los esfuerzos han resultado infructuosos. Y, aunque se observan repeticiones de segmentos completos en los distintos textos que componen el subcorpus español, no tenemos certeza de que se recurra a herramientas de traducción asistida por ordenador.

En los dos subapartados siguientes se van a analizar algunos rasgos de las traducciones al español de las alertas de retirada de alimentos del FSIS, recogidas en el corpus ALER_USA. En primer

16 Se trata del registro ALER_USA/EN1139, disponible en el siguiente URL: https://www.fsis.usda. gov/wps/portal/fsis/topics/recalls-and-publichealth-alerts / recall-case-archive/archive/2018/ recall-116-2018-release. 
lugar, se analizarán algunos aspectos generales, para seguidamente ver cómo se traducen los términos más relevantes para este tipo de texto en relación con la inocuidad alimentaria.

\subsection{Traducción de aspectos generales}

En los apartados siguientes se enumeran algunos aspectos de la traducción, como errores comunes y traducción de topónimos y unidades de medida. Estos elementos presentan un bajo nivel de especialización, pero su traducción errónea o imprecisa afecta a la calidad general del texto y puede complicar en ocasiones la comprensión de este por parte de los lectores hispanohablantes.

\subsubsection{Errores mecanográficos y ortográficos}

Es llamativo el elevado número de errores mecanográficos y faltas de ortografía en ALER_USA/ES. Algunos de ellos se deben a casos de vacilación entre la ce, la zeta y la ese: *envaces (tres casos), *sepa (tres casos; Ejemplo 3), *onsas (un caso), *expanción (un caso). Aunque no se registra un número elevado de apariciones por cada caso, estos sí constituyen errores bastante llamativos, que, por lo demás, podrían haberse detectado fácilmente con la herramienta de corrector ortográfico. En ALER_REF no se registran casos de los errores que se acaban de mencionar.

\section{Ejemplo 3}

\section{ALER_USA/ES0488}

Sin embargo, la compañía, de forma inadvertida, no completo las pruebas completas para confirmar la sepa de E. coli

Otros errores se deben a la ausencia de tildes, como sucede en el caso de * completo del ejemplo anterior o en las palabras terminadas en -ción, que deben llevar tilde por ser palabras agudas terminadas en ene. Se registran numerosos casos (112 casos; $187 /$ millón). ${ }^{17}$ Los ejemplos más destaca-

17 A fin de permitir la comparación entre los dos corpus, ALER_USA y ALER_REF, se recurrirá a la frecuencia normalizada por millón en algunas ocasiones a dos son los que siguen: *contaminacion (49 casos), *inspeccion (24), * rotulacion (14) o *notificacion (7). A la inversa, también se detectan tildes en palabras que no deberían llevarla, de acuerdo con las normas de acentuación: ( ${ }^{*} e s t a$, forma verbal de estar, 213 casos; Ejemplo 4), *distribuído (y demás flexiones, 67), *ingles (en referencia al idioma, 42; ejemplo 4), * numero (sustantivo, 27), *incluído (13) $\mathrm{y}$ * continua (forma verbal de continuar, 11).

\section{Ejemplo 4}

\begin{abstract}
ALER_USA/ES0214
El siguiente producto se encuentra bajo este alerta a la salud pública (el nombre del producto esta mencionado en ingles)
\end{abstract}

Los errores en la atildación no son exclusivos de los textos traducidos de ALER_USA, ya que en ALER_REF se observan también numerosos errores de esta misma categoría. En concreto, en las palabras terminadas en -ción, se registran 135 casos en los que no figura la tilde, con una frecuencia normalizada (192/millón) incluso más elevada que en los textos traducidos de ALER_USA/ES. Algunos ejemplos son *informacion, *proteccion o *exportacion, con seis casos cada uno (cf. Ejemplo 5). ${ }^{18}$

\section{Ejemplo 5}

ALER_REF/COL05

Confirmar con Invima si es necesario realizar alguna verificacion de proceso previa a la exportacion y emisión del certificado.

En cuanto a la presencia de tildes erróneas, también se identifican algunos errores: * numero (sustantivo, diez casos), * continua (forma verbal

\footnotetext{
lo largo de este artículo, lo que se indicará de manera expresa. Se empleará solo el número entero, sin la parte decimal, para facilitar la lectura de los datos.

18 En el caso de los ejemplos procedentes del corpus de referencia, se emplea en primer lugar el nombre del corpus (ALER_REF), seguido del subcorpus COL para los textos procedentes de Colombia, MÉX para los de México y ESP para los de España- y del número de identificación del texto.
} 
de continuar, tres casos), *esta (forma verbal de estar, dos casos), *ingles (dos casos) e *incluidos (un caso). El número de errores por presencia de tildes incorrectas es, con mucho, más reducido en ALER_REF que en ALER_USA/ES, pues se dan $25 /$ millón casos en el corpus de referencia, frente a los 623/millón del corpus de alertas de los Estados Unidos.

\subsubsection{Topónimos de los Estados Unidos}

El número de topónimos en ALER_USA es muy elevado, ya que en las alertas de retirada de alimentos figuran tanto el lugar donde radica la fábrica o el distribuidor responsable del producto en cuestión como los estados o las ciudades en las que se tiene constancia de que se ha comercializado el producto. Los topónimos que aparecen en los registros de ALER_USA se refieren a tres grandes grupos: al país, a los estados y a las ciudades. Por cuestiones de espacio, se hará alusión únicamente a los topónimos del segundo grupo.

Se han comprobado en ALER_USA/EN todas las apariciones, 4075, de los cincuenta estados del país y sus correspondientes equivalentes en el subcorpus de textos traducidos. Al mismo tiempo, se han consultado en tres fuentes (Real Academia Española, 2005; Martínez de Sousa, 2012; Navarro, 2020) las recomendaciones que se dan para las traducciones al español de estos topónimos. ${ }^{19}$ De los cincuenta estados, las fuentes consultadas ofrecen denominaciones tradicionales en español para veintidós de ellos (cf. Anexo, columna Recomendación): en cuatro casos, al menos alguna de las fuentes da un topónimo coincidente con el inglés: Alaska, Florida, Texas y Washington. En los dieciocho estados restantes, ${ }^{20}$ se observa en ALER_USA/ES

19 Todos los datos aparecen en el Anexo.

20 Estos estados son los que siguen, según las fuentes consultadas: Carolina del Norte, Carolina del Sur, Dakota del Norte, Dakota del Sur, Hawái/Hawai, Luisiana, Míchigan, Minesota, Misisipi/Misisipí, la tendencia mayoritaria a recurrir a endónimos en español, y no a los exónimos que figuran en las tres fuentes consultadas, pues se localizan 897 endónimos frente a 271 casos de exónimos en español. Solamente en las denominaciones de dos estados, South Dakota y North Carolina, se recurre de manera mayoritaria a los exónimos Dakota del Sur (64,2 \% de los casos totales del estado) y Carolina del Norte (53\%), respectivamente. Otros exónimos que son relativamente frecuentes si se analiza el total de casos para cada estado son Carolina del Sur (44,4 \%), Nueva York (40,9\%), Nuevo México/Méjico (36,6 \%) y Oregón (25,3 \%).

Son relevantes también algunos casos en los que se emplean grafías erróneas para los nombres de los estados, no sabemos si por errores mecanográficos o por intentos de traducción no exitosos. Algunos de estos casos son * Conneticut (6 casos; Ejemplo 6), *Óregon (6) y *Wisconcin (3). En algunas ocasiones, se advierte que los errores se producen por vacilación ante dobles consonantes. *Pensylvania (9 casos), *Mississipi (4), *Misssissipi (1), *Massachussetts (2), * Massachusets (1) y * Masssachusetts (1) son ejemplos de ello.

En cualquier caso, lo más llamativo en lo referente a las traducciones de topónimos de los estados son las omisiones que se producen. Si bien son solo 31 los casos de omisión en el subcorpus español (apenas un 0,75 \% del total), pueden tener repercusiones graves por la falta de precisión del mensaje traducido. Los topónimos de los estados aparecen en las alertas alimentarias sobre todo en los títulos, para localizar dónde se encuentra la empresa a la que afecta la alerta (véase el ejemplo 6), y en el apartado donde se informa de los estados en los que se ha comercializado o distribuido el producto. Si se omite el nombre del estado en cuestión, es posible que

\footnotetext{
Misuri, Nuevo/Nueva Hampshire, Nueva Jersey, Nueva York, Nuevo México/Méjico, Ohío, Oregón, Pensilvania y Virginia Occidental.
} 
Ejemplo 6

\begin{tabular}{l|l}
\multicolumn{1}{c}{ Inglés } & \multicolumn{1}{c}{ Español } \\
ALER_USA/ENO201 & ALER_USA/ESO2O1 \\
Connecticut Firm Recalls & UNA FIRMA EN CONNETICUT RETIRA \\
Appetizer Products & DEL MERCADO PRODUCTOS DE \\
for POSSible Listeria & APERIIIVO DEBIDO A UNA POSIBLE \\
Contamination & CONTAMINACION CON LISTERIA
\end{tabular}

Ejemplo 7

\begin{tabular}{l:l}
\multicolumn{1}{c}{ Inglés } & \multicolumn{1}{c}{\begin{tabular}{c}
\multicolumn{1}{c}{ Español } \\
ALER_USA/ENO637
\end{tabular}} \\
These items were sold to & ALER_USA/ESO637 \\
one distributor, who then & Estos productos fueron \\
sold it to restaurants in & vendidos a distribuidores \\
Arizona, California, New & de chefs, los cuales a \\
Jersey, Pennsylvania, & su vez los vendieron a \\
Maryland, Nevada and & restaurantes localizados \\
New York. & en Chicago, Los Ángeles,
\end{tabular}

algún consumidor considere que la alerta no le afecta, lo que podría tener consecuencias muy graves para la salud si llega a consumir el producto. La mayoría de las omisiones en la traducción de los nombres de los estados se producen en este apartado concreto. Así sucede en el Ejemplo 7, donde se omiten en la traducción las referencias a cinco estados: Arizona, California, Nueva Jersey, Pensilvania y Maryland y, en su lugar, aparecen dos ciudades que no figuran en el texto origen. Se trata, por lo demás, de una alerta de clase I, el nivel más alto posible, por un etiquetado incorrecto. Este error en la traducción posiblemente se deba a haber reaprovechado texto de alguna alerta previa, que, sin embargo, no hemos localizado en el corpus. Una forma posible de evitar errores de este tipo, siempre y cuando se empleen herramientas de traducción asistida por ordenador, consiste en recurrir a algún programa de control de calidad — caso de Xbench (Apsic, 2011) - que permita elaborar listas de comprobación para detectar incoherencias entre los dos textos.

\subsubsection{Unidades de medida}

En lo relativo a las unidades de medida, se emplea frecuentemente el sistema anglosajón de unidades en ALER_USA/ES para las unidades de peso. Las unidades más empleadas son las siguientes:

- pound $/ l b=$ libra (1944 casos), lb[.] (405)

- ounce/oz = onza (278), oz[.] (557), *onsas (1)

- fluid ounce/fl oz =fl.oz. (7)

De forma prácticamente testimonial, se localizan 26 casos en los que tanto en el texto origen como en el traducido se ofrece la equivalencia de los pesos en el sistema métrico decimal. Lo razonable es que en las traducciones al español se mantenga el sistema anglosajón por dos razones: en primer lugar, porque los destinatarios de los textos traducidos serán eminentemente hablantes de español residentes en los Estados Unidos, y en la mayoría de los casos las unidades de medida que conocerán mejor serán las del sistema anglosajón. En segundo lugar, porque estas unidades aparecen normalmente haciendo alusión a las distintas presentaciones de los productos; por este motivo es importante que el consumidor pueda identificar si ha adquirido el producto al que se está refiriendo la alerta. Por lo tanto, las traducciones que se ofrece de las unidades son correctas en líneas generales, aunque en numerosas ocasiones la grafía de estas no es acorde a la norma.

En lo relativo a la forma de indicar la temperatura - habitualmente para ofrecer indicaciones sobre cómo cocinar determinados alimentos para que sean seguros-, la escala termométrica que se emplea en los textos traducidos es la de Fahrenheit, con 67 casos en ALER_USA/ES, y en 23 de estos casos se ofrece en el texto traducido además el equivalente en grados Celsius. No se registran casos en los que se ofrezca la temperatura solo en esta última escala.

\subsection{Términos relevantes relacionados con la inocuidad alimentaria}

Mediante el uso de Sketch Engine se ha obtenido la lista de las palabras clave más relevantes 
Tabla 1. Palabras clave más relevantes en ALER_USA/EN

\begin{tabular}{|c|c|c|}
\hline Orden & Palabra clave & $\begin{array}{c}\text { Frecuencia } \\
\text { absoluta }\end{array}$ \\
\hline $1 .{ }^{\circ}$ & FSIS & 3806 \\
\hline $2 .^{\circ}$ & misbranding & 722 \\
\hline $3 .^{\circ}$ & undeclared & 775 \\
\hline $4 .^{\circ}$ & allergen & 1140 \\
\hline $5 . .^{\circ}$ & Listeria & 387 \\
\hline $6 . .^{\circ}$ & monocytogenes & 329 \\
\hline $7 .^{\circ}$ & 0157:H7 & 330 \\
\hline $8 .{ }^{\circ}$ & recall & 6687 \\
\hline $9 .{ }^{\circ}$ & beef & 2661 \\
\hline $10 .^{\circ}$ & boneless & 227 \\
\hline $11.0^{\circ}$ & USDA & 1212 \\
\hline $12 .^{\circ}$ & sausage & 855 \\
\hline $13 .^{\circ}$ & jerky & 213 \\
\hline $14 .^{\circ}$ & pork & 1104 \\
\hline $15 .^{\circ}$ & foods & 867 \\
\hline
\end{tabular}

de ALER_USA/EN, para lo que se ha utilizado como corpus de referencia el corpus English Web 2015 (enTenTen15), de más de 13190 millones de palabras. En la Tabla 1 aparecen las treinta primeras palabras clave de ALER_USA/ EN, organizadas por calidad de palabra clave.

Los términos de la Tabla 1 que se relacionan con la inocuidad alimentaria son los siguientes: FSIS, misbranding, undeclared, allergen, Listeria [monocytogenes], o157:H7, recall, USDA, listeriosis, Salmonella, inspection, coli, contaminate, mislabel y adulterate. Comentaremos a continuación los que se consideran más relevantes desde el punto de vista de la traducción, ya sea por la amplísima variedad de equivalentes registrada o por las dificultades que plantea la búsqueda de equivalentes de algunos términos.

\subsection{1. misbranding}

La segunda palabra clave de la lista es el sustantivo misbranding, empleada cuando el producto "contiene ingredientes que no se declaran

\begin{tabular}{|c|c|c|}
\hline Orden & Palabra clave & $\begin{array}{c}\text { Frecuencia } \\
\text { absoluta }\end{array}$ \\
\hline $16^{\circ}$ & listeriosis & 120 \\
\hline $17 .^{\circ}$ & poultry & 841 \\
\hline $18^{\circ}$ & Salmonella & 305 \\
\hline $19 .^{\circ}$ & patty & 390 \\
\hline $20 .^{\circ}$ & Est. & 727 \\
\hline $21 .^{\circ}$ & inspection & 2696 \\
\hline $22 .^{\circ}$ & coli & 449 \\
\hline $23 .^{\circ}$ & veal & 141 \\
\hline $24 .^{\circ}$ & contaminate & 489 \\
\hline $25^{\circ}$ & mislabel & 105 \\
\hline $26 .^{\circ}$ & UPC & 176 \\
\hline $27 .^{\circ}$ & products & 1029 \\
\hline $28 .^{\circ}$ & chicken & 2247 \\
\hline $29 .^{\circ}$ & adulterate & 97 \\
\hline $30 .^{\circ}$ & sirloin & 94 \\
\hline
\end{tabular}

en las etiquetas del producto"n1 (U.S. Food Safety and Inspection Service, 2013a, sec. Attachment 2). Este sustantivo aparece en 722 ocasiones en ALER_USA/EN (o 1568/millón), y, en la versión en español de la directiva 8080.1 aparece traducido como mal etiquetado (U.S. Food Safety and Inspection Service, 2013b, sec. Anexo 2). En cuanto a los equivalentes del subcorpus español, su variedad es enorme, como se puede ver en la Tabla 2 , donde aparecen agrupados por lemas y sin tener en cuenta los errores de mayúsculas y acentuación.

Se aprecia en la Tabla 2 una preponderancia indiscutible de los equivalentes con el verbo rotular o palabras derivadas (656 casos, el $91 \%$ del total; Ejemplo 8), mientras que las opciones que contienen etiquetar o sus derivadas son solo 58, el $8 \%$. Del $1 \%$ restante destaca una traducción errónea - sin el beneficio de una inspección, correspondiente

21 "contains ingredients that are not declared on the product labeling". 
Tabla 2. Equivalentes de misbranding en ALER_USA/ES

\begin{tabular}{|c|c|c|c|}
\hline Lema & Forma & $\begin{array}{c}\text { Frecuencia } \\
\text { absoluta }\end{array}$ & $\begin{array}{c}\text { Frecuencia } \\
\text { normalizada }\end{array}$ \\
\hline \multirow{5}{*}{ rotular } & error de rotulación & 507 & 847 \\
\hline & error en rotulación & 115 & 192 \\
\hline & rotulación errónea & 15 & 25 \\
\hline & rotulado erróneamente & 14 & 23 \\
\hline & error en la rotulación & 5 & 8 \\
\hline \multirow{5}{*}{$\begin{array}{l}\text { etiquetar/ } \\
\text { etiqueta }\end{array}$} & mal etiquetado & 46 & 76 \\
\hline & erróneamente etiquetado & 5 & 8 \\
\hline & etiquetado erróneamente & 4 & 6 \\
\hline & error en la etiqueta & 2 & 3 \\
\hline & error de etiquetado & 1 & 1 \\
\hline \multirow{4}{*}{ Otros } & Omisión & 5 & 8 \\
\hline & sin el beneficio de una inspección & 1 & 1 \\
\hline & marcación incorrecta & 1 & 1 \\
\hline & marca incorrecta & 1 & 1 \\
\hline
\end{tabular}

Ejemplo 8

\begin{tabular}{l|l}
\multicolumn{1}{c}{ Inglés } & \multicolumn{1}{c}{\begin{tabular}{c}
\multicolumn{1}{c}{ Español } \\
ALER_USA/ENO497
\end{tabular}} \\
$\begin{array}{l}\text { FSIS is investigating this } \\
\text { episode of misbranding } \\
\text { that lead to the recall. }\end{array}$ & $\begin{array}{l}\text { FSIS COntinúa investigando } \\
\text { el episodio de error de } \\
\text { rotulación que propició } \\
\text { esta retirada. }\end{array}$
\end{tabular}

al sintagma preposicional without the benefit of inspection- $\mathrm{y}$ a cinco casos de omisión. Los casos de este $1 \%$, como se ha señalado en situaciones anteriores, son de gran relevancia, ciertamente no por su número, pero sí por su alcance, ya que al encontrarse todos en el título de la alerta impiden que el lector pueda identificar adecuadamente la razón que ha motivado la retirada de los alimentos.

La búsqueda de los equivalentes de la Tabla 2 en ALER_REF ofrece muy pocos casos, tan solo los lemas etiquetado erróneamente y error de etiquetado (3 casos en cada uno; 4/millón). No obstante, se encuentra en este mismo corpus un número elevado de apariciones de rotular y sus derivadas (118 casos; 168/millón) y, sobre todo, de etiquetar y palabras derivadas (748; 1068/millón), muy al contrario de lo que sucede en ALER_USA/ES, donde predomina el empleo de rotular.

\subsection{2. allergen}

Este término, en inocuidad alimentaria, hace referencia a "proteínas de cacahuetes y frutos secos de árbol, pescado, marisco, trigo, soja, huevos o leche, que desencadenan un mecanismo inmunológico representado casi exclusivamente por reacciones adversas considerables mediadas por la inmunoglobulina E"22 (Hosu et al., 2018, p. 49). Según estas mismas autoras, los alérgenos alimentarios son un gravísimo problema sanitario mundial, y el aumento en los últimos decenios de las alergias a los alimentos supone un desafío capital para la industria alimentaria. Esta relevancia se pone de manifiesto al comprobar los datos resumidos

\footnotetext{
22 "proteins from nuts and tree nuts, fish, shellfish, wheat, soy, eggs or milk which trigger an immunologic mechanism represented almost exclusively by IgE-mediated severe adverse reactions".
} 
Tabla 3. Equivalentes de allergen en ALER_USA/ES

\begin{tabular}{|c|c|c|}
\hline Lema & $\begin{array}{c}\text { Frecuencia } \\
\text { absoluta }\end{array}$ & $\begin{array}{l}\text { Frecuencia } \\
\text { normalizada }\end{array}$ \\
\hline alérgeno & 1071 & 1529 \\
\hline alergeno & 349 & 498 \\
\hline Omisión & 11 & 15 \\
\hline alergéno & 5 & 7 \\
\hline allergeno & 3 & 4 \\
\hline alrgeno & 1 & 1 \\
\hline
\end{tabular}

de alertas alimentarias de 2019, comentados en el apartado Introducción, donde se aprecia que la presencia de alérgenos no declarados en los productos fue la tercera causa de retirada de alimentos (U.S. Food Safety and Inspection Service, 2020).

En la Tabla 3 se muestran los lemas equivalentes en español para las 1440 apariciones de allergen en el subcorpus ALER_USA/EN.

Los dos más frecuentes, alérgeno y alergeno, son válidos de acuerdo con varias fuentes (Navarro, 2020; Igea Aznar, 2021), si bien se señala que la fórmula preferida es la primera, para estar en consonancia con "los términos científicos que incorporan el sufijo de origen griego 'geno'[, que] se acentúan en esdrújula, por ejemplo, antígeno, estrógeno, broncógeno, cancerígeno o piógeno" (Igea Aznar, 2021; las cursivas son nuestras).

Tanto en ALER_USA/ES como en ALER_REF, alérgeno es, con mucho, la forma más habitual. En el corpus de alertas de los Estados Unidos se registran 1071 casos (1521/millón) frente a alergeno, que es un tercio menos frecuente (349; $498 /$ millón). En el corpus de referencia, se localizan 92 casos de alérgeno (131/millón) frente a solo 7 (10/millón) de alergeno. En cualquier caso, el problema radica en el uso combinado en el mismo archivo de las dos opciones, alérgeno y alergeno, cosa que debería evitarse a nuestro juicio, y aun así se da en 33 de los registros de ALER_USA/ES (Ejemplo 9).

\section{Ejemplo 9}

\begin{abstract}
ALER_USA/ES0018
Una firma de Accomac, vA., retira aproximadamente 24,710 libras de productos de pollo, pecho sin piel y sin hueso por que estos podrían contener alergenos sin declarar. Los productos contienen aliños Italianos, que incluyen leche, que es conocida como un alérgeno y que no esta declarado en la etiqueta.
\end{abstract}

Son ocho los productos que aparecen asociados a allergen al realizar la búsqueda mediante la opción Collocations de Sketch Engine con un límite inferior de cinco instancias en el corpus. Se trata en concreto de soy (116 casos), milk (106), wheat (96), egg (64), peanut (27), whey (14), anchovy (14), nut (14), lecithin (11) y fish (5). Del total de 467 casos, 21 son traducciones erróneas o imprecisas. Aunque es una proporción exigua sobre el total, ya que apenas supone el $4 \%$ de casos, es evidente que se debe ser especialmente cauto ante la traducción de estos elementos, puesto que la detección de alérgenos no identificados hace que la alerta alimentaria sea habitualmente de clase I (U.S. Food Safety and Inspection Service, 2013a, sec. Attachment 2). Las consecuencias para la salud de los consumidores pueden ser nefastas; véase en este sentido el Ejemplo 10, donde soy se traduce erróneamente como trigo. Este error puede hacer que los consumidores

\section{Ejemplo 10}

\begin{tabular}{|c|c|}
\hline $\begin{array}{l}\text { Inglés } \\
\text { ALER_USA/ENO228 } \\
\text { WASHINGTON, Jan. 28, } 2011 \\
\text { - Nina Mia, Inc., a Fullerton, } \\
\text { Calif., establishment is } \\
\text { recalling approximately } \\
654 \text { pounds of frozen } \\
\text { veal ravioli products } \\
\text { because they contain an } \\
\text { undeclared allergen, soy, } \\
\text { which is not declared on } \\
\text { the label. }\end{array}$ & $\begin{array}{l}\text { Español } \\
\text { ALER_USA/ESO228 } \\
\text { WASHINGTON, } 28 \text { de enero } \\
\text { del 2011- Nina Mia, Inc., } \\
\text { un establecimiento en } \\
\text { Fullerton, California, esta } \\
\text { retirando del mercado } \\
\text { aproximadamente } 654 \\
\text { libras de productos } \\
\text { congelados ravioli } \\
\text { de ternera debido al } \\
\text { contenido del alérgeno } \\
\text { trigo, conocido como un } \\
\text { potencial alérgeno y este } \\
\text { no está declarado en la } \\
\text { etiqueta }\end{array}$ \\
\hline
\end{tabular}


que lean la alerta en español y sean alérgicos al trigo desechen el producto innecesariamente $\mathrm{y}$, al contrario, quienes sean alérgicos a la soja no lo descarten, lo que puede comportar consecuencias muy graves, incluso la muerte.

\subsection{3. recall}

Se han analizado las traducciones de los 2369 casos en que recall funciona como sustantivo. Se trata de un sustantivo de gran importancia, puesto que da nombre al procedimiento mediante el cual el FsIs notifica que se va a retirar un producto o alimento, y que en la traducción al español de la directiva ya mencionada recibe el nombre de retiro del producto del mercado (U.S. Food Safety and Inspection Service, 2013 b, p. 2). En la Tabla 4 se muestran los equivalentes organizados por lemas, para que su lectura sea más sencilla.

Como se puede apreciar, la opción más frecuente es el recurso al sustantivo retirada, con 2119 casos en total (3541/millón), seguidos a mucha distancia de retiro (102; 170/millón) y distintas formas verbales de retirar (69; 115/millón). Las omisiones en esta ocasión no son relevantes para la comprensión del mensaje, salvo en dos casos puntuales. En cuanto a los usos comparados en ALER_REF, observamos que se emplea retirada en 111 ocasiones (164/millón) — todas ellas en textos procedentes de España-, mientras que de retiro se localizan 83 casos (118/millón) - 17 de Colombia y 66 de México-. La consulta en el Corpus del español del siglo XXI (Real Academia Española, n.d.), por su parte, indica que en textos de los Estados Unidos se localizan 31 casos/ millón de retiro, mientras que el uso de retirada es algo menor, 12/millón. Sobre los equivalentes de recall, afirma Saladrigas Isenring lo siguiente:

en la legislación europea recall figura traducido como "recuperación" (Directiva 2001/95/CE del Parlamento Europeo y del Consejo, Reglamento [CE] n. ${ }^{\circ}$ 765/2008 del Parlamento Europeo y del Consejo) o
Tabla 4. Equivalentes en ALER_USA/ES del sustantivo recall

\begin{tabular}{|c|c|c|}
\hline Lema & Forma & $\begin{array}{c}\text { Frecuencia } \\
\text { absoluta }\end{array}$ \\
\hline retira $(n)$ & retira & 9 \\
\hline \multirow{6}{*}{$\begin{array}{l}\text { retirada } \\
\text { (n) }\end{array}$} & retirada & 1899 \\
\hline & retirada de alimentos & 135 \\
\hline & retirada de productos & 65 \\
\hline & retirada del mercado & 16 \\
\hline & $\begin{array}{l}\text { retirada de productos del } \\
\text { mercado }\end{array}$ & 3 \\
\hline & $\begin{array}{l}\text { retirada de alimentos del } \\
\text { mercado }\end{array}$ & 1 \\
\hline \multirow[t]{2}{*}{ retirar (v) } & retirar & 56 \\
\hline & retirar del mercado & 13 \\
\hline \multirow[t]{4}{*}{ retiro $(n)$} & retiro & 85 \\
\hline & retiro del mercado & 10 \\
\hline & retiro de productos & 5 \\
\hline & $\begin{array}{l}\text { retiro de alimentos del } \\
\text { mercado }\end{array}$ & 2 \\
\hline \multirow[t]{4}{*}{ Otros } & Omisión & 55 \\
\hline & alerta & 7 \\
\hline & comunicado & 6 \\
\hline & memoria & 1 \\
\hline
\end{tabular}

como "retirada" (Directiva 91/412/CEE). En Hispanoamérica se usa más "retiro" (COFEPRIS, ANMAT, INVIMA) (Saladrigas Isenring, 2021).

En ALER_USA/ES se advierte, por lo tanto, que la forma más empleada en el español peninsular, retirada, es veinte veces más frecuente que retiro, forma esta última que según la autora mencionada es más empleada en Hispanoamérica y que era de suponer que sería más frecuente en el español de los Estados Unidos de las alertas del FsIs.

\subsubsection{Escherichia coli, Listeria monocytogenes y Salmonella}

Por último, nos vamos a centrar en la traducción de términos relacionados con dos bacterias, Escherichia coli y Listeria monocytogenes, y el género Salmonella, y que entre los tres motivaron la emisión de 16 alertas alimentarias en el 
Tabla 5. Equivalentes de Listeria monocytogenes en ALER_USA/ES

\begin{tabular}{|c|c|}
\hline ALER_USA/ES & $\begin{array}{c}\text { Frecuencia } \\
\text { absoluta }\end{array}$ \\
\hline Listeria monocytogenes & 247 \\
\hline Listeria & 20 \\
\hline Listaría monocytogenes & 6 \\
\hline Listeria monogytogenes & 2 \\
\hline L. monocytogenes & 2 \\
\hline Omisión & 2 \\
\hline Lm & 1 \\
\hline Lysteria monocytogenes & 1 \\
\hline Listeria monocytogene & 1 \\
\hline Listería monocytogenes & 1 \\
\hline Listeria Monocytogenesis & 1 \\
\hline
\end{tabular}

año 2019 en los Estados Unidos, como se ha mencionado en el apartado Introducción.

En la Tabla 5 se muestran los equivalentes en español de las 284 apariciones de Listeria monocytogenes en ALER_USA/EN, con 9 formas distintas en los textos traducidos al español. El equivalente más frecuente es Listeria monocytogenes, que es el nombre que recibe esta bacteria en español (Navarro, 2020) y que se debe escribir en cursiva - y en mayúscula el nombre de género- (Carande Herrero, 2012, p. 4; Martínez de Sousa, 2012, pp. 463-464; Claros Díaz, 2016, pp. 73, 77). Los 37 casos restantes, un $12 \%$, se reparten entre imprecisiones (Listeria, que hace referencia únicamente al género), abreviaciones, formas con errores mecanográficos ( ${ }^{*}$ Listaría, *Listería, *Monocytogenesis, entre otros) y dos casos de omisión (Ejemplo 11).

De acuerdo con Martínez de Sousa, "cuando en una misma unidad textual se menciona más de una vez la misma bacteria, en la segunda $\mathrm{y}$ siguientes menciones se suele abreviar el sustantivo, siempre que no dé lugar a confusiones" (2012, p. 287), apreciación de la que también se hace eco Navarro (2020). En el caso
Ejemplo 11

\begin{tabular}{|c|c|}
\hline $\begin{array}{l}\text { Inglés } \\
\text { ALER_USA/ENO435 } \\
\text { Microbial testing and } \\
\text { other findings as part } \\
\text { of the food safety } \\
\text { assessment indicated that } \\
\text { additional product may } \\
\text { have been contaminated } \\
\text { due to harborage of } \\
\text { Listeria monocytogenes } \\
\text { within the facility. }\end{array}$ & $\begin{array}{l}\text { Español } \\
\text { ALER_USA/ESO435 } \\
\text { Un muestreo } \\
\text { microbiológico y otros } \\
\text { hallazgos como parte } \\
\text { de una evaluación de } \\
\text { inocuidad indicaron que } \\
\text { otros productos estaban } \\
\text { contaminados. }\end{array}$ \\
\hline
\end{tabular}

de Listeria monocytogenes, los usos abreviados son minoritarios en ALER_USA: 43 apariciones de L. monocytogenes en EN y 38 en Es, y 16 de $L m$ en el subcorpus inglés frente a 12 de $L m$ en español. Donde sí se muestra mayoritario el uso abreviado es en relación con otra bacteria, Escherichia coli, que, según Navarro, "puede verse abreviada en inglés de múltiples maneras: E. Coli, Ecoli, e-coli, Es. coli, Esch. coli, etcétera" (2020). En efecto, la abreviación E. coli es muy frecuente tanto en el subcorpus inglés como en el español, como se aprecia en la Tabla 6, en la que se advierte que, de las 449 apariciones de esta bacteria, solamente el $2 \%$ de los casos en inglés - e incluso algo menos en español, $1,7 \%$ - corresponde a la forma desarrollada. No se cumple, por lo tanto, la recomendación de usar la forma abreviada cuando se haya mencionado previamente el nombre completo en el mismo texto: al analizar los textos del subcorpus español individualmente, vemos que solamente en seis archivos se da el uso de ambas formas, completa y abreviada, para hacer referencia a la bacteria, mientras que en

Tabla 6. Lemas relacionados con Escherichia coli en ALER_USA

\begin{tabular}{|l|c|c|c|}
\hline Forma & $\begin{array}{c}\text { Frec. abs. } \\
\text { ALER_USA/EN }\end{array}$ & $\begin{array}{l}\text { Frec. abs. } \\
\text { ALER_USA/ES }\end{array}$ \\
E. coli & 427 & 441 \\
E.coli & 13 & 3 \\
Escherichia coli & 9 & 8
\end{tabular}


227 archivos solamente aparece la forma abreviada, sin mención previa a la denominación completa.

El último caso que veremos atiende a la traducción de Salmonella y salmonela (nombres científico y común del género, respectivamente; Real Academia Nacional de Medicina, 2012), que, además, suele confundirse con salmonelosis ('enfermedad causada por salmonelas', Navarro, 2020). De acuerdo con Navarro, se trata de una equivocación

sumamente frecuente en el lenguaje coloquial y en el ámbito periodístico, donde es ya habitual oír hablar, por ejemplo, de un brote de salmonela o a salmonella outbreak cuando lo que quieren decir es un brote de salmonelosis, o de salmonellosis infection cuando lo que se quiere decir es infección por salmonelas (o salmonelosis a secas). (2020; las cursivas son nuestras)

Esta confusión está presente en ALER_USA, como se puede ver en la Tabla 7, donde, de los 302 casos totales de Salmonella, 26 de ellos (56/millón) aparecen incorrectamente
Ejemplo 12

\begin{tabular}{|c|c|}
\hline $\begin{array}{l}\text { Inglés } \\
\text { ALER_USA/EN } 1240 \\
\text { This outbreak strain } \\
\text { of Salmonella Dublin } \\
\text { did not identify any } \\
\text { antibiotic resistance. }\end{array}$ & $\begin{array}{l}\text { Español } \\
\text { ALER_USA/ES } 1240 \\
\text { Esta cepa del brote } \\
\text { de Salmonella Dublín } \\
\text { no identificó ninguna } \\
\text { resistencia a los } \\
\text { antibióticos. }\end{array}$ \\
\hline
\end{tabular}

asociados al sustantivo outbreak en el subcorpus inglés, cifra que se reduce a la mitad, 13 (21/millón), en el caso del subcorpus español (Ejemplo 12). Esta situación no es exclusiva del corpus ALER_USA, ya que en ALER_REF se detectan once casos (15/millón) de brote de Salmonella en textos de España y México. En cuanto a la traducción que se da del nombre de la bacteria, se aprecia que la práctica totalidad de los casos en español son correctos (263 casos de Salmonella, 10 de salmonela y 1 de brote de salmonelosis).

Donde surgen mayores discrepancias, sin embargo, es en la denominación de la enfermedad, salmonellosis en inglés, cuyo equivalente español más frecuente es salmonelosis —en minúscula y

Tabla 7. Equivalentes de Salmonella y salmonelosis en ALER_USA/ES

\begin{tabular}{|c|c|c|c|}
\hline Forma & $\begin{array}{l}\text { Frec. abs. } \\
\text { ALER_USA/EN }\end{array}$ & Forma & $\begin{array}{l}\text { Frec. abs. } \\
\text { ALER_USA/ES }\end{array}$ \\
\hline \multirow{4}{*}{$\begin{array}{l}\text { Salmonella } \\
\text { outbreak/ } \\
\text { outbreak of } \\
\text { Salmonella }\end{array}$} & \multirow{4}{*}{26} & brote de Salmonella & 12 \\
\hline & & brote de enfermedad(es) & 8 \\
\hline & & Otros & 5 \\
\hline & & brote con Salmonella & 1 \\
\hline \multirow{5}{*}{ Salmonella } & \multirow{5}{*}{276} & Salmonella & 263 \\
\hline & & salmonela & 10 \\
\hline & & brote de salmonelosis & 1 \\
\hline & & Salmonela & 1 \\
\hline & & Omisión & 1 \\
\hline \multirow{5}{*}{ salmonellosis } & \multirow{5}{*}{74} & salmonelosis & 53 \\
\hline & & salmonellosis & 14 \\
\hline & & Salmonelosis & 5 \\
\hline & & $\begin{array}{l}\text { enfermedad causada } \\
\text { por Salmonella }\end{array}$ & 1 \\
\hline & & listeriosis & 1 \\
\hline
\end{tabular}


de redondo (Martínez de Sousa, 2012, p. 356), al ser un sustantivo común-: las 74 instancias en ALER_USA/EN arrojan un total de 20 casos erróneos (un $27 \%$ ), por aparecer en mayúsculas, por tener una grafia incorrecta o por traducirse erróneamente como listeriosis.

Sobre el uso del artículo ante los nombres científicos de las tres bacterias, afirma Martínez de Sousa que en "textos escritos en español, es normal utilizar artículo ante los nombres científicos o de divulgación científica (2012, p. 464), mientras que Claros Díaz afirma que "nunca llevan artículo" (2016, p. 99). Por su parte, la Real Academia Nacional de Medicina, en referencia a cada uno de los tres géneros de bacterias, indica que "[c] omo nombre propio, no suele ir precedido de artículo; si lo precisa, es femenino" (2012). Lo cierto es que la tendencia al uso del artículo ante estas tres bacterias en ALER_USA/ES es solamente puntual: de un total de 1011 apariciones de las tres — véase la Tabla 8-, solo en 59 ocasiones (el $5 \%$ ) aparecen con artículo, y esta proporción es aún menor en ALER_REF (no llega al $3 \%$ ). Lo que sí resulta llamativo es el género de los artículos cuando acompañan a las bacterias: en ambos corpus el uso del género femenino es el habitual, salvo en el caso de Escherichia coli, del que se dan 39 casos de artículo masculino en ALER_USA/ES, frente a solo 10 del femenino.

Tabla 8. Casos totales de apariciones de Listeria monocytogenes, Escherichia coli y Salmonella en ALER_ USA/ES Y ALER_REF (Nota: entre paréntesis, coaparición de artículos masculino y femenino).

\begin{tabular}{|l|c|c|}
\hline \multicolumn{1}{|c}{ Forma } & \multicolumn{1}{c}{$\begin{array}{l}\text { Frec. abs. } \\
\text { ALER_USA/ES }\end{array}$} & $\begin{array}{c}\text { Frec. abs. } \\
\text { ALER_REF }\end{array}$ \\
\hdashline $\begin{array}{l}\text { Listeria } \\
\text { monocytogenes }\end{array}$ & $256(0+5)$ & $122(0+1)$ \\
\hdashline $\begin{array}{c}\text { Escherichia/E. coli } \\
\text { Salmonella }\end{array}$ & $458(39+10)$ & $75(0+2)$ \\
\hline
\end{tabular}

\section{Conclusiones}

Según afirman Hallman y Cuite, el objetivo final de cualquier alerta de retirada de alimentos es "evitar enfermedades, dolencias y fallecimientos innecesarios que pueden originarse en el consumo de un producto contamina-

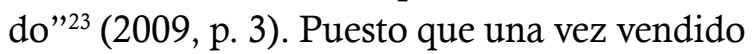
el producto tienen que ser los consumidores quienes, de manera individual, lo localicen y eliminen convenientemente, llegar al mayor público posible es de vital importancia. En el caso de los Estados Unidos, habida cuenta del gran número de hispanohablantes, la traducción de estas alertas al español es de gran utilidad para que el mensaje se pueda difundir ampliamente.

Para el presente estudio se ha compilado un corpus, que es paralelo y alineado en el nivel de la oración, de todas las alertas de retirada de alimentos del U.S. Food Safety and Inspection Service que se han traducido al español, de forma tal que el corpus, ALER_USA, se compone de 1277 bitextos. También se ha compilado un corpus de referencia, ALER_REF, integrado por alertas de retirada de alimentos y otros textos relacionados de organismos oficiales de México, Colombia y España. Ambos corpus han demostrado ser herramientas de gran valor para este trabajo, y pensamos que pueden tener numerosas aplicaciones futuras para la traducción - y la enseñanza de la traducción- de este tipo de textos o de textos sobre inocuidad alimentaria del inglés al español y viceversa.

En cuanto a los resultados principales del trabajo, en primer lugar, se han estudiado algunos rasgos generales de los textos traducidos. En este sentido, llama la atención el abundante número

23 "to prevent unnecessary illness, suffering, and death that may result from consuming a contaminated product". 
de errores ortográficos y mecanográficos presentes en ALER_USA/ES, aunque es justo indicar que estos errores también están presentes en los textos, escritos originariamente en español, de ALER_REF. Así sucedía, por ejemplo, con las palabras terminadas en -ción, que en 135 ocasiones aparecían en el corpus de referencia sin tilde. Seguidamente, al analizar la traducción de los topónimos referidos a los cincuenta estados de los Estados Unidos, se observa una tendencia general en los textos traducidos a emplear los endónimos en lugar de los exónimos, aunque en algunos topónimos concretos el uso del exónimo es abundante (Carolina del Sur, Nueva York), cuando no directamente mayoritario (Dakota del Sur y Carolina del Norte). Por último, se comprueba que las traducciones mantienen las unidades de medida del sistema anglosajón y la escala Fahrenheit para indicar la temperatura, lo cual es positivo, ya que estas son las unidades que debe de emplear la mayoría de los destinatarios de los textos traducidos.

Seguidamente, de las treinta palabras clave más relevantes de ALER_USA/EN, se han tomado las que guardan relación directa con la inocuidad alimentaria y son más interesantes desde el punto de vista de la traducción. En tres de los casos estudiados, los sustantivos misbranding, allergen y recall, se trata de palabras esenciales para este tipo de texto: las dos primeras porque son razones que muy frecuentemente desencadenan la retirada de alimentos, y la tercera porque es el nombre que recibe el proceso del que se informa en la alerta. En general, se advierte un número elevado de equivalentes para la traducción de estos tres términos, cuando lo que sería conveniente en estos textos es una mayor coherencia terminológica para que los consumidores puedan asimilar el mensaje más fácilmente.

Se han analizado finalmente las distintas traducciones que se dan de dos bacterias - Listeria monocytogenes y Escherichia coli- y del género
Salmonella, así como de las enfermedades que pueden causar. Los textos traducidos tienen nuevamente una variedad de equivalentes enorme, como puede verse en las tablas respectivas, y la influencia del inglés se advierte tanto en la grafía de las palabras (*salmonellosis en español) como en el uso de abreviaciones (E. coli frente a Escherichia coli). Igualmente, es llamativo el número tan alto de usos erróneos de outbreak en los textos en inglés y de su equivalente en español, brote, que se deberían emplear en relación con enfermedades y no con las bacterias que las provocan. Esta tendencia, en cualquier caso, no es exclusiva del corpus principal del trabajo, pues en el de referencia también se registran casos erróneos de brote.

Las imprecisiones, omisiones y traducciones erróneas de los elementos analizados del corpus son de especial relevancia y están presentes en prácticamente todos los elementos estudiados: nombres de estados, alérgenos, procesos del aseguramiento de la inocuidad alimentaria y denominaciones de las bacterias. Si bien cuantitativamente su importancia podría tildarse de menor, lo cierto es que estos poco frecuentes casos pueden tener una relevancia enorme, ya que, como se ha visto en los apartados correspondientes, pueden comprometer muy gravemente la salud de los consumidores, por no permitir la correcta localización e identificación del producto.

Por último, no debe olvidarse que el objetivo de una buena comunicación de las alertas de retirada de alimentos no es solo conseguir llegar a un número lo más elevado posible de consumidores, sino que, como afirman Hallman y Cuite, también se pretende que los consumidores puedan tomar las medidas necesarias de forma correcta y ejecutarlas satisfactoriamente (2009, p. II). Por ello, es necesario, que el mensaje en nuestro caso, traducido al español- llegue a los consumidores de forma clara, precisa y lo más homogénea posible. La aplicación de una 
serie de medidas orientadas a la mejora de la traducción - por ejemplo, mediante la elaboración de listas de comprobación que detecten omisiones e imprecisiones, y el uso adecuado de herramientas de traducción asistida por ordenador- podría conseguir mensajes que se transmiten de manera más eficiente, algo que es de agradecer cuando lo que está en juego es la salud de los consumidores y la economía de muchas empresas y sectores productivos.

\section{Referencias}

Apsic. (2011). Xbench (2.9.474). Apsic.

Brougher, C., y Greene, J. L. (2000). The USDA's authority to recall meat and poultry products.

Carande Herrero, V. (2012). Nomenclatura de Salmonella para uso corriente. Punto y Coma, 130, 4-5.

Carlson, C. C., y Peake, W. O. (2012). Rethinking food recall communications for consumers. Iridescent, 2(3), 11-23. https://doi.org/10.108 0/19235003.2012.11428511

Charlebois, S., Massow, M. Von, y Pinto, W. (2015). Food recalls and risk perception: An exploratory case of the XL Foods and the biggest food recall in Canadian history. Journal of Food Products Marketing, 21(1), 27-43. https:// doi.org/10.1080/10454446.2013.856055

Chiaro, D., y Rossato, L. (2015). Introduction: Food and translation, translation and food. The Translator, 21(3), 237-243. https://doi.org $/ 10.1080 / 13556509.2015 .1110934$

Claros Díaz, M. G. (2016). Cómo traducir y redactar textos cientificos en español: Reglas, ideas y consejos (2. ${ }^{\mathrm{a}}$ ed.). Fundación Dr. Antonio Esteve.

Danino, C. (2018). Introduction. Corpus, 18, 1-10. https://doi.org/10.4000/corpus.3099

Díaz Flores, I. (2018). La terminología de la gastronomía puertorriqueña: reflexiones en torno a su trasfondo y representación. CLINA, 4(2), 181-205. https://doi.org/10.14201/clina201842181205

Faya Ornia, G. (2014). Revisión y propuesta de clasificación de corpus. Babel. Revue internationale de la traduction/International Journal of Translation,
60(2), 234-252. https://doi.org/10.1075/babel.60.2.06fay

Fernández Nistal, P. (2020). Los corpus como herramienta de traducción para los traductores e intérpretes del siglo xxI: el caso del chorizo ibérico de bellota. En S. Álvarez Álvarez y M. T. Ortega Antón (Eds.), Perfiles estratégicos de traductores e intérpretes: la transmisión de la información experta multilingüe en la sociedad del conocimiento del siglo XXI (pp. 143-160). Comares.

Fernández Vítores, D. (2020). El español, una lengua viva. Informe 2020. En Instituto Cervantes, El español en el mundo 2020. Anuario del Instituto Cervantes (pp. 6-70). Instituto Cervantes, Bala Perdida.

Fuentes-Luque, A. (2017). An approach to analysing the quality of menu translations in southern Spain restaurants. Journal of Multilingual and Multicultural Development, 38(2), 177-188. https://doi.org/10.1080/01434632.2016.118 7154

Haigh, M. M., y Brubaker, P. (2010). Examining how image restoration strategy impacts perceptions of corporate social responsibility, organization-public relationships, and source credibility. Corporate Communications: An International Journal, 15(4), 453-468. https://doi. org/10.1108/13563281011085538

Hallman, W. K., y Cuite, C. L. (2009). Food recalls and the American public: Improving communications. https://doi.org/10.7282/T3639RQX

Hosu, O., Selvolini, G., y Marrazza, G. (2018). Recent advances of immunosensors for detecting food allergens. Current Opinion in Electrochemistry, 10, 149-156. https://doi.org/10.1016/j. coelec.2018.05.022

Igea Aznar, J. M. (2021). Diccionario inglés-español de alergología e inmunología clínica, 3. ${ }^{a}$ edición, versión 3.03. Cosnautas.

Ji, M. (2010). Phraseology in corpus-based translation studies. Peter Lang. https://doi. org/10.3726/978-3-0353-0014-7

Kilgarriff, A., Baisa, V., Bušta, J., Jakubíček, M., Kovář, V., Michelfeit, J., Rychlý, P., y Suchomel, V. (2014). The Sketch Engine: ten years on. Lexicography, 1(1), 7-36. https://doi. org/10.1007/s40607-014-0009-9 
Leiva Rojo, J. (2018). Diseño y compilación de corpus paralelos alineados: dificultades y (algunas) soluciones en el ejemplo de un corpus de textos museísticos traducidos (inglés-español). Revista de Lingüistica y Lenguas Aplicadas, 13, 59-73. https://doi.org/10.4995/rlyla.2018.7912

Li, S. (2019). A corpus-based multimodal approach to the translation of restaurant menus. Perspectives, 27(1), 1-19. https://doi.org/10.10 80/0907676x.2018.1483408

Martínez de Sousa, J. (2012). Manual de estilo de la lengua española (4. ${ }^{\mathrm{a}}$ ed.). Trea.

McEnery, T., y Hardie, A. (2012). Corpus linguistics: Method, theory and practice. Cambridge University Press. https://doi.org/10.1017/ CBO9780511981395

Moreno-Fernández, F. (2019). Hacia un corpus del español en los Estados Unidos. Debate para la génesis del proyecto CORPEEU. Informes del Observatorio/Observatorio Reports. https://doi. org/10.15427/OR049-03/2019SP

Moreno Paz, M. del C., y Rodríguez Tapia, S. (2015). La situación de la traducción agroalimentaria en la investigación y la formación en España. SKOPOS. Revista Internacional de Traducción e Interpretación, 6, 135-154.

Nádvorníková, O. (2017). Pièges méthodologiques des corpus parallèles et comment les éviter. Corela, HS-21, 1-28. https://doi.org/10.4000/ corela.4810

National Food Service Management Institute. (2012). Responding to a food recall: Procedures for recalls of USDA foods. https://www.fns. usda.gov/ofs/responding-food-recall-procedures-recalls-usda-foods

Navarro, F. A. (2020). Diccionario de dudas y dificultades de traducción del inglés médico. (3. ${ }^{a}$ edición, versión 3.16). Cosnautas.

Ortego-Antón, M. T. (2020). Las fichas descriptivas de embutidos en español y en inglés: Un análisis contrastivo de la estructura retórica basado en corpus. Revista Signos, 53(102), 170-194. https://doi.org/10.4067/S071809342020000100170

Ortego-Antón, M. T. (2019). La terminología del sector agroalimentario (español-inglés) en los estudios contrastivos y de traducción especializada basados en corpus: los embutidos. Peter Lang. https:// doi.org/10.3726/b15808

Real Academia Española. (n.d.). Corpus del español del siglo XXI. Recuperado de https://www.rae. es/banco-de-datos/corpes-xxi [Último acceso: 31-01-2021].

Real Academia Española. (2005). Diccionario panhispánico de dudas. Real Academia Española; Asociación de Academias de la Lengua Española; Santillana.

Real Academia Nacional de Medicina. (2012). Diccionario de términos médicos. Panamericana.

Rodríguez Rodríguez, F. (2013). La traducción en el sector agroalimentario: una simbiosis en auge. SKOPOS. Revista Internacional de Traducción e Interpretación, 2, 155-172.

Ross, D. (2018). Small corpora and low-frequency phenomena: Try and beyond contemporary, standard English. Corpus, 18. https://doi. org/10.4000/corpus. 3574

Saladrigas Isenring, M. V. (2021). Diccionario inglés-español de investigación clínica, versión 1.19. Cosnautas.

Scallan, E., Griffin, P. M., Angulo, F. J., Tauxe, R. V., y Hoekstra, R. M. (2011). Foodborne illness acquired in the United states-Unspecified agents. Emerging Infectious Diseases, 17(1), 16-22. https://doi.org/10.3201/eid1701. P21101

SDL Group. (2018). sDL Trados Studio 2019. SDL Group.

Statistical Atlas. (2018). Languages in the United States. https://statisticalatlas.com/United-States/Languages

The Economist Intelligence Unit. (2019). 2019 Global Food Security Index. The Economist.

U.S. Census Bureau. (2015). Detailed languages spoken at home and ability to speak english for the population 5 years and over: 2009-2013. https://www.census.gov/data/tables/2013/ demo/2009-2013-lang-tables.html

U.S. Census Bureau. (2019). Language spoken at home by ability to speak english for the population 5 years and over. Census Reporter. 
U.S. Food Safety and Inspection Service. (2021). Current recalls and alerts. https://www.fsis. usda.gov/wps/portal/fsis/topics/recallsand-public-health-alerts/current-recalls-andalerts

U.S. Food Safety and Inspection Service. (2020). Summary of recall cases in calendar year 2019. https://www.fsis.usda.gov/recallsummaries

U.S. Food Safety and Inspection Service. (2013a). FSIS directive 8080.1, revision 7. Recall of meat and poultry products (pp. 1-41). United States Department of Agriculture, Food Safety and Inspection Service.

U.S. Food Safety and Inspection Service. (2013b). Directiva del FSIS 8080.1, revisión 7. Retiro del mercado de productos de carnes y de aves de corral (pp. 1-72). United States Department of Agriculture, Food Safety and Inspection Service.

U.S. General Accounting Office. (2010). Food safety: Actions needed by USDA and FDA to ensure that companies promptly carry out recalls, GAO/RCED-00195. https://doi.org/10.1089/blr.2006.9996

U.S. Government Accountability Office. (2004). Food safety: USDA and FDA need to better ensure prompt and complete recalls of potentially unsafe food, GAO-05-51 a. www.gao.gov/cgi-bin/getrpt?GAO-05-51

Vidal Claramonte, M. Á., y Faber, P. (2017). Translation and food: The case of mestizo writers. Journal of Multicultural Discourses, 12(3), 189204. https://doi.org/10.1080/17447143.201 7.1339352

Wu, F. (2017). Responsibility, recalls, and reputations of organizations: theory-based experimental studies to improve food safety crisis communication. Rutgers, The State University of New Jersey.

Zanettin, F. (2012). Translation-driven corpora: Corpus resources for descriptive and applied translation studies. Routledge.

\section{Anexo}

Frecuencia de los nombres de los estados en ALER_USA/EN Y equivalentes en ALER_USA/ES

\begin{tabular}{|c|c|c|c|c|}
\hline ALER_REF/EN & Frecuencia & ALER_REF/ES & Frecuencia & Recomendación \\
\hline Alabama & 37 & Alabama & 37 & \\
\hline Alaska & 16 & Alaska & 16 & Alaska, DPD \\
\hline \multirow[t]{2}{*}{ Arizona } & \multirow[t]{2}{*}{78} & Arizona & 77 & \\
\hline & & Omisión & 1 & \\
\hline Arkansas & 44 & Arkansas & 44 & \\
\hline \multirow[t]{3}{*}{ California } & \multirow[t]{3}{*}{334} & California & 328 & \\
\hline & & Omisión & 5 & \\
\hline & & Calilfornia & 1 & \\
\hline Colorado & 113 & Colorado & 113 & \\
\hline \multirow[t]{2}{*}{ Connecticut } & \multirow[t]{2}{*}{60} & Connecticut & 54 & \\
\hline & & Conneticut & 6 & \\
\hline Delaware & 23 & Delaware & 23 & \\
\hline \multirow[t]{3}{*}{ Florida } & \multirow[t]{3}{*}{127} & Florida & 123 & (la) Florida, DPD \\
\hline & & la Florida & 3 & \\
\hline & & Omisión & 1 & \\
\hline \multirow[t]{2}{*}{ Georgia } & \multirow[t]{2}{*}{108} & Georgia & 107 & \\
\hline & & Omisión & 1 & \\
\hline \multirow[t]{2}{*}{ Hawaii } & \multirow[t]{2}{*}{43} & Hawaii & 34 & \multirow{2}{*}{$\begin{array}{l}\text { Hawái, DPD, MELE } \\
\text { Hawai, DDTM }\end{array}$} \\
\hline & & Hawai & 7 & \\
\hline
\end{tabular}


Frecuencia de los nombres de los estados en ALER_USA/EN Y equivalentes en ALER_USA/ES (Cont.)

\begin{tabular}{|c|c|c|c|c|}
\hline ALER_REF/EN & Frecuencia & ALER_REF/ES & Frecuencia & Recomendación \\
\hline & & Hawái & 2 & \\
\hline Idaho & 29 & Idaho & 29 & \\
\hline \multirow{3}{*}{ Illinois } & \multirow[t]{3}{*}{159} & Illinois & 155 & \\
\hline & & llinois & 2 & \\
\hline & & Omisión & 2 & \\
\hline \multirow{2}{*}{ Indiana } & \multirow[t]{2}{*}{79} & Indiana & 78 & \\
\hline & & Omisión & 1 & \\
\hline lowa & 83 & lowa & 83 & \\
\hline \multirow{2}{*}{ Kansas } & \multirow[t]{2}{*}{40} & Kansas & 39 & \\
\hline & & Omisión & 1 & \\
\hline \multirow{2}{*}{ Kentucky } & \multirow[t]{2}{*}{47} & Kentucky & 46 & \\
\hline & & Kentuky & 1 & \\
\hline \multirow{4}{*}{ Lovisiana } & \multirow[t]{4}{*}{57} & Lovisiana & 46 & \multirow{3}{*}{$\begin{array}{l}\text { (LA) Luisiana, DPD } \\
\text { Luisiana, MELE Y DDTM }\end{array}$} \\
\hline & & Luisiana & 6 & \\
\hline & & Lousiana & 4 & \\
\hline & & Lovisiane & 1 & \\
\hline Maine & 43 & Maine & 43 & \\
\hline \multirow{2}{*}{ Maryland } & \multirow[t]{2}{*}{84} & Maryland & 82 & \\
\hline & & Omisión & 2 & \\
\hline \multirow{5}{*}{ Massachusetts } & \multirow[t]{5}{*}{99} & Massachusetts & 84 & \\
\hline & & Massachussets & 11 & \\
\hline & & Massachussetts & 2 & \\
\hline & & Massachusets & 1 & \\
\hline & & Masssachusetts & 1 & \\
\hline \multirow{3}{*}{ Michigan } & \multirow[t]{3}{*}{106} & Michigan & 104 & Míchigan, DDTM \\
\hline & & Mitigan & 1 & \\
\hline & & Omisión & 1 & \\
\hline \multirow{3}{*}{ Minnesota } & \multirow[t]{3}{*}{93} & Minnesota & 90 & Minesota, DDTM \\
\hline & & Minesota & 2 & \\
\hline & & Minneota & 1 & \\
\hline \multirow{4}{*}{ Mississippi } & \multirow[t]{4}{*}{35} & Mississippi & 28 & \multirow{4}{*}{$\begin{array}{l}\text { Misisipi, DPD Y DDTM } \\
\text { Misisipí, DPD Y MELE }\end{array}$} \\
\hline & & Mississipi & 4 & \\
\hline & & Misisipi & 2 & \\
\hline & & Misssissipi & 1 & \\
\hline \multirow{2}{*}{ Missouri } & \multirow[t]{2}{*}{71} & Missouri & 70 & \multirow{2}{*}{ Misuri, DPD, MELE Y DDTM } \\
\hline & & Misuri & 1 & \\
\hline Montana & 12 & Montana & 12 & \\
\hline Nebraska & 44 & Nebraska & 44 & \\
\hline \multirow{2}{*}{ Nevada } & 45 & Nevada & 42 & \\
\hline & & Omisión & 3 & \\
\hline New Hampshire & 21 & New Hampshire & 21 & $\begin{array}{l}\text { Nuevo Hampshire, DPD } \\
\text { Nueva Hampshire, DPD, } \\
\text { MELE Y DDTM }\end{array}$ \\
\hline
\end{tabular}


Frecuencia de los nombres de los estados en ALER_USA/EN Y equivalentes en ALER_USA/ES (Cont.)

\begin{tabular}{|c|c|c|c|c|}
\hline ALER_REF/EN & Frecuencia & ALER_REF/ES & Frecuencia & Recomendación \\
\hline \multirow{3}{*}{ New Jersey } & \multirow[t]{3}{*}{129} & New Jersey & 95 & \multirow{2}{*}{$\begin{array}{l}\text { Nueva Jersey, DPD, MELE } \\
\text { Y DDTM }\end{array}$} \\
\hline & & Nueva Jersey & 30 & \\
\hline & & Omisión & 4 & \\
\hline \multirow{6}{*}{ New Mexico } & \multirow[t]{6}{*}{30} & New Mexico & 14 & \multirow{5}{*}{$\begin{array}{l}\text { Nuevo México, DPD, MELE } \\
\text { y DDTM } \\
\text { Nuevo Méjico, DPD }\end{array}$} \\
\hline & & Nuevo México & 9 & \\
\hline & & Nuevo Mexico & 3 & \\
\hline & & Nuevo Méjico & 2 & \\
\hline & & Nueva Mexico & 1 & \\
\hline & & Omisión & 1 & \\
\hline \multirow{3}{*}{ New York } & \multirow[t]{3}{*}{227} & New York & 133 & \multirow{3}{*}{$\begin{array}{l}\text { Nueva York, DPD y MELE } \\
\text { [estado] de Nueva York, } \\
\text { DDTM }\end{array}$} \\
\hline & & Nueva York & 93 & \\
\hline & & Omisión & 1 & \\
\hline \multirow{3}{*}{ North Carolina } & \multirow[t]{3}{*}{77} & Carolina del Norte & 41 & \multirow{3}{*}{$\begin{array}{l}\text { Carolina del Norte, DPD, } \\
\text { MELE Y DDTM }\end{array}$} \\
\hline & & North Carolina & 35 & \\
\hline & & Nort Carolina & 1 & \\
\hline \multirow{2}{*}{ North Dakota } & \multirow[t]{2}{*}{13} & North Dakota & 12 & \multirow{2}{*}{$\begin{array}{l}\text { Dakota del Norte, DPD, } \\
\text { MELE Y DDTM }\end{array}$} \\
\hline & & Dakota del Norte & 1 & \\
\hline \multirow{2}{*}{ Ohio } & \multirow[t]{2}{*}{182} & Ohio & 180 & Ohío, MELE \\
\hline & & Omisión & 2 & \\
\hline Oklahoma & 58 & Oklahoma & 58 & \\
\hline \multirow{3}{*}{ Oregon } & \multirow[t]{3}{*}{71} & Oregon & 47 & \multirow{2}{*}{ Oregón, DPD, MELE Y DDTM } \\
\hline & & Oregón & 18 & \\
\hline & & Óregon & 6 & \\
\hline \multirow{3}{*}{ Pennsylvania } & \multirow[t]{3}{*}{152} & Pennsylvania & 119 & \multirow{2}{*}{$\begin{array}{l}\text { Pensilvania, DPD, MELE Y } \\
\text { DDTM }\end{array}$} \\
\hline & & Pensilvania & 24 & \\
\hline & & Pensylvania & 9 & \\
\hline Rhode Island & 21 & Rhode Island & 21 & \\
\hline \multirow{2}{*}{ South Carolina } & \multirow[t]{2}{*}{45} & South Carolina & 25 & Carolina del Sur, DPD, MELE \\
\hline & & Carolina del Sur & 20 & Y DDTM \\
\hline South Dakota & 14 & Dakota del Sur & 9 & Dakota del Sur, DPD, MELE \\
\hline SOUII LAKOId & & South Dakota & 5 & Y DDTM \\
\hline Tennessee & 63 & Tennessee & 63 & \\
\hline & 367 & Texas & 362 & Texas, Tejas (en España), \\
\hline Texas & & Tejas & 3 & DPD \\
\hline & & Omisión & 2 & Tejas, MELE Y DDTM \\
\hline & 73 & Utah & 71 & \\
\hline Utah & & Uta & 1 & \\
\hline & & Omisión & 1 & \\
\hline Vermont & 31 & Vermont & 31 & \\
\hline Virginia & 103 & Virginia & 103 & \\
\hline Washington & 139 & Washington & 121 & estado de Washington, \\
\hline $\begin{array}{l}\text { Washington State/ } \\
\text { state }\end{array}$ & 22 & Estado de Washington & 37 & DDTM \\
\hline
\end{tabular}


Frecuencia de los nombres de los estados en ALER_USA/EN Y equivalentes en ALER_USA/ES (cont.)

\begin{tabular}{|c|c|c|c|c|}
\hline ALER_REF/EN & Frecuencia & ALER_REF/ES & Frecuencia & Recomendación \\
\hline \multirow{2}{*}{$\begin{array}{l}\text { Washington } \\
\text { Washington State/ } \\
\text { state }\end{array}$} & & Omisión & 2 & \\
\hline & & Washinton & 1 & \\
\hline \multirow{3}{*}{ West Virginia } & \multirow[t]{3}{*}{24} & West Virginia & 17 & \multirow{2}{*}{$\begin{array}{l}\text { Virginia Occidental, DPD, } \\
\text { MELE Y DDTM }\end{array}$} \\
\hline & & Virginia Occidental & 4 & \\
\hline & & Virginia del Oeste & 3 & \\
\hline \multirow{3}{*}{ Wisconsin } & \multirow[t]{3}{*}{89} & Wisconsin & 85 & \\
\hline & & Wisconcin & 3 & \\
\hline & & Omisión & 1 & \\
\hline Wyoming & 15 & Wyoming & 15 & \\
\hline
\end{tabular}

Nota. En la columna Recomendación aparecen los equivalentes para los topónimos en español de tres fuentes: DPD (Real Academia Española, 2005), mele (Martínez de Sousa, 2012, p. 623) y DDTM (Navarro, 2020). En el caso de MELE, solo figuran los exónimos.

Cómo citar este artículo: Leiva Rojo, J. (2021). Inocuidad y alertas alimentarias: una visión léxico-traductológica (inglés-español). Mutatis Mutandis, Revista Latinoamericana de Traducción, 14(2), 345-371. https://doi.org/10.17533/udea.mut.v14n2a04 